\title{
The difference in the survival rate of patients with metastatic renal cell carcinoma in the intermediate-risk group of the Memorial Sloan Kettering Cancer Center criteria
}

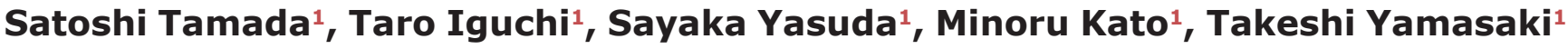 \\ and Tatsuya Nakatani ${ }^{1}$ \\ ${ }^{1}$ Department of Urology, Osaka City University Graduate School of Medicine, Abeno-ku, Osaka 545-8585, Japan \\ Correspondence to: Satoshi Tamada, email: s-tamada@med.osaka-cu.ac.jp \\ Keywords: molecular targeted therapy; renal cell carcinoma; Memorial Sloan Kettering Cancer Center criteria; metastasis; \\ intermediate risk \\ Received: April 23, $2018 \quad$ Accepted: May 18, $2018 \quad$ Published: June 12, 2018 \\ Copyright: Tamada et al. This is an open-access article distributed under the terms of the Creative Commons Attribution License \\ 3.0 (CC BY 3.0), which permits unrestricted use, distribution, and reproduction in any medium, provided the original author and \\ source are credited.
}

\section{ABSTRACT}

Objectives: To investigate the necessity of stratifying patients in the intermediaterisk group of the Memorial Sloan Kettering Cancer Center (MSKCC) criteria in a realworld population of patients with metastatic renal cell carcinoma.

Patients and Methods: We retrospectively analyzed 234 consecutively treated patients who had received molecular targeted drugs. We examined the difference between progression-free survival and overall survival among patients in the intermediate-risk group of MSKCC criteria. We divided the intermediate group into two subgroups as follows: patients positive for only one risk factor (Int-1) and those positive for two risk factors (Int-2) including performance status, serum hemoglobin level, time from diagnosis to treatment, and corrected calcium and lactate dehydrogenase levels. Next, we evaluated the association between the number of metastatic organs, the presence of pancreatic metastasis, Int-1 or Int-2 grouping, and overall survival.

Results: The median overall survival was 41.2 months. The median overall survival of the favorable-, intermediate-, and poor-risk groups of the MSKCC criteria were 91.0, 33.6, and 15.2 months, respectively. Patient characteristics were similar between the Int-1 and Int-2 groups. Increased positivity for risk factors of MSKCC classification between the two groups was for performance status and serum hemoglobin level. Progression-free survival and overall survival of the Int-1 group were significantly higher than those of the Int-2 group. In Cox proportional stepwise multivariate analysis, the Int-1 and Int-2 classification was an independent risk factor for overall survival.

Conclusion: Patients in the intermediate-risk group had different prognoses depending on the number of positive risk factors.

\section{INTRODUCTION}

The survival rate of patients with metastatic renal cell carcinoma has improved remarkably since the introduction of molecular targeted drugs [1-4]. We classified the prognoses of patients with metastatic renal cell carcinoma $(\mathrm{mRCC})$ and used the classification as an index in selecting a treatment approach. The Memorial Sloan Kettering Cancer Center (MSKCC) risk classification is a survival risk classification advocated by Motzer et al. [5] before treatment using molecular targeted drugs became common. This classification is reportedly associated with prognosis even in the era of molecular targeted drugs [6] and is still widely used. However, the 
International Metastatic Renal Cell Carcinoma Database Consortium (IMDC) risk classification advocated by Heng et al. [7] was established in the era of molecular targeted drugs and is also used as widely as the MSKCC risk classification. There is also another risk classification targeted for Japanese patients, which was remodeled to be used more practically by incorporating factors attributable to metastatic organs [8].

However, patients in the intermediate group accounted for about half of all the patients. Moreover, the intermediate-risk group involves 1 or 2 risk factors; thus, there is a great variability among the patients. Consequently, it has not been decided whether it is appropriate to treat the intermediate-risk group as one group. Sella et al. based on six clinical trials data consisting in well-selected patients treated with sunitinib only, reported the heterogeneity of patients identified as having intermediate risk using the MSKCC risk criteria [9].

In this study, therefore, we performed a retrospective analysis of patients treated with tyrosine kinase inhibitors and mammalian target of rapamycin inhibitor in the intermediate-risk group within a realworld Japanese population to investigate the necessity of stratifying patients in the intermediate-risk group. Optimal classification for Japanese population may predict treatment effect or investigate a treatment approach in the future.

\section{RESULTS}

Table 1 shows the characteristics of the study population. Patients in the intermediate risk class accounted for about $50 \%$ of all risk classes. The median overall survival (OS) was 41.2 months (Supplementary Figure 1). The median OS of the favorable-, intermediate-, and poor-risk groups based on the MSKCC criteria were 91.0, 33.6, and 15.2 months, respectively (Supplementary Figure 2). Patients in the favorable-risk group had a significantly prolonged survival than those in the other groups (hazard ratio (HR) 0.22, 95\% confidence interval (CI) $0.11-0.44, \mathrm{p}<0.001)$. Conversely, patients in the poor-risk group had a significantly shorter survival time compared to those in the other groups (HR 3.04, 95\% CI $1.95-4.74, \mathrm{p}<0.001)$ and compared to those in the intermediate-risk group alone (HR 2.15, 95\% CI 1.373.39). The median OS using the first-line treatmentssunitinib, sorafenib, and temsirolimus were 69.6, 33.6, and 11.8 months, respectively.

Table 2 shows the characteristics of patients in the intermediate-risk class. Patient characteristics were similar between the two subgroups. Increased positivity for risk factors of the MSKCC classification between Int- 1 and Int- 2 groups were for performance status and serum hemoglobin level. The median OS using the firstline treatments- sunitinib and sorafenib were 43.4 and
30.7 months, respectively, in the intermediate risk group (log-rank test, $\mathrm{p}=0.103$ ). The progression-free survival (PFS) and OS of the Int-1 group were significantly higher than those of the Int-2 group (Figures 1, 2). Patients in the Int-1 group had a significantly shorter survival than those in the favorable group (HR 2.88, 95\% CI 1.32$6.30, p=0.007)$. No significant difference in survival was found between the Int-2 and poor-risk groups (HR 1.42, CI $0.87-2.29, \mathrm{p}=0.151)$. The median OS using the firstline drugs- sunitinib and sorafenib were 44.1 and 43.6 months, respectively, in the Int-1 group, (log-rank test, $\mathrm{p}=0.438$ ) and were 27.2 and 15.2 months, respectively, in the Int-2 group, (log-rank test, $\mathrm{p}=0.099$ ). We evaluated the risk factors of the MSKCC criteria to determine the risk factors that affect survival rate between the two groups, but no significant difference was observed in any of the risk factors (performance status (PS), 0 vs $\geq 1$, HR 0.62 , 95\% CI 0.35-1.08; serum hemoglobin level, < lower limit of normal (LLN) vs $\geq$ LLN, HR 1.41, 95\% CI 0.82-2.43; time from diagnosis to treatment, $<1$ year vs $\geq 1$ year, $\mathrm{HR}$ $1.47,95 \%$ CI 0.85-2.52; corrected calcium level, $<10 \mathrm{mg} /$ $\mathrm{dL}$ vs $\geq 10 \mathrm{mg} / \mathrm{dL}, \mathrm{HR} 0.40,95 \%$ CI $0.15-1.08$; lactate dehydrogenase (LDH) level, $<1.5 x$ upper limit of normal (ULN) vs $1.5 x U L N$, HR $0.98,95 \%$ CI 0.39-2.48).

Fifty-six out of the 126 patients in the intermediate group died. Cox proportional stepwise multivariate analysis showed that the Int-1 and Int-2 classification was an independent risk factor for OS (HR 1.91, 95\% CI 1.11$3.30, \mathrm{p}=0.019)$. (Table 3)

\section{DISCUSSION}

To the best of knowledge, we reported here for the first time an investigation of the necessity of stratifying patients in the intermediate-risk group of the MSKCC risk classification within a real-world Japanese population. We demonstrated that there was a significant difference in the survival period between Int- 1 and Int-2 groups of the intermediate-risk group. This finding suggests that we need to subcategorize the intermediate-risk group to predict treatment effect or investigate a treatment approach in the future.

In addition to other studies, we previously reported that patients in the intermediate-risk group account for about $50 \%$ of patients with metastatic renal carcinoma and their survival rate falls between those of the favorable- and poor-risk groups $[8,10,11]$. However, a subcategorization of the intermediate-risk group has not been considered. In recent years, however, clinical trials have been conducted within the intermediate- and poor-risk groups alone or occasionally, clinical trials have been conducted to prove efficacy within these groups alone $[12,13]$. Accordingly, a need has arisen to change the treatment approach to match the individual risk groups. However, since the intermediate-risk group involves 1 or 2 risk factors, there is a great variability among the patients and consequently, 
Table 1: Patients characteristics and treatments $(\mathrm{N}=\mathbf{2 3 4})$

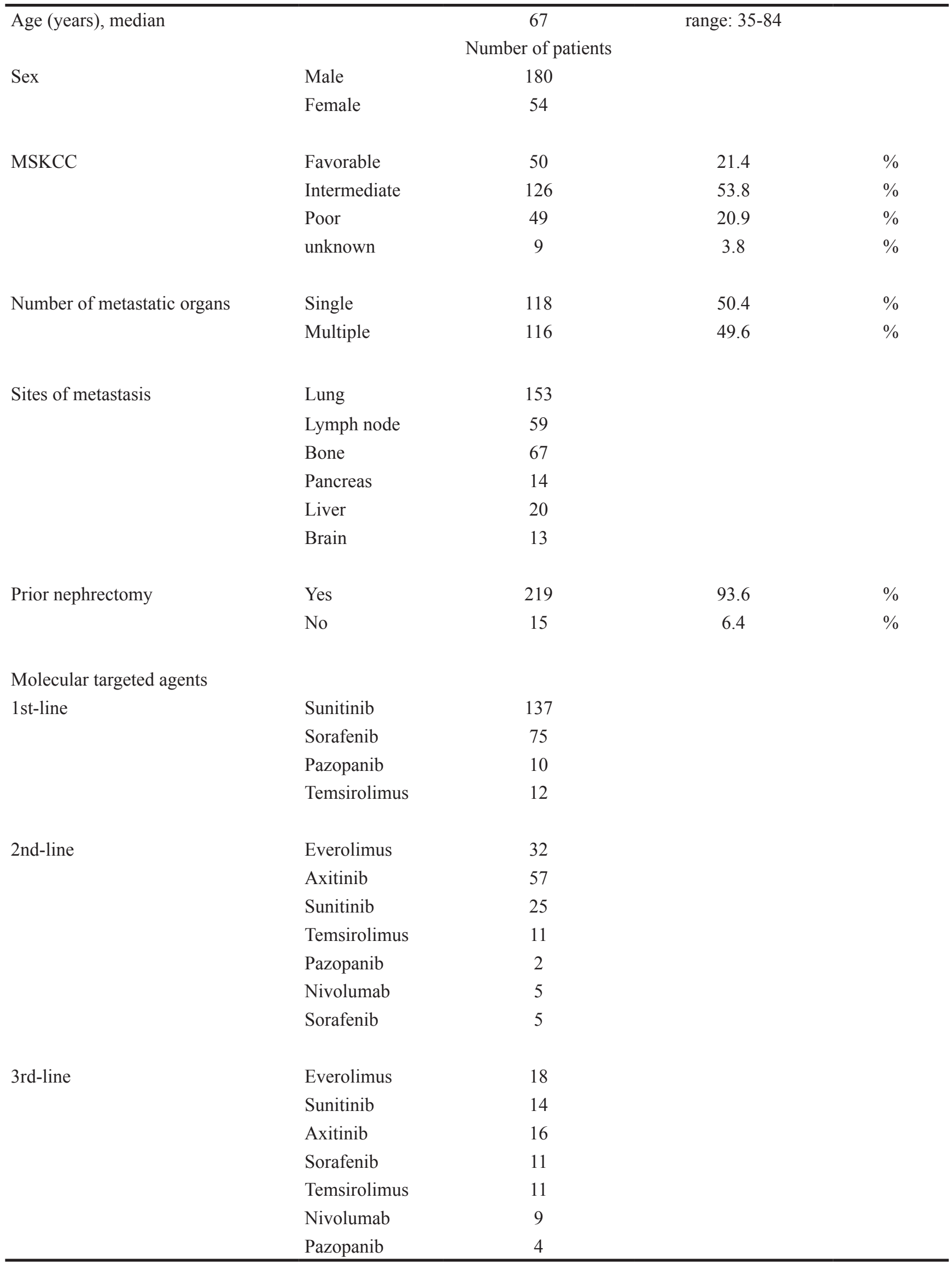


Table 2: Patients characteristics and treatments in intermediate group $(N=126)$

\begin{tabular}{|c|c|c|c|c|c|}
\hline \multirow{3}{*}{ Age (years), median } & & \multirow{2}{*}{\multicolumn{2}{|c|}{$\begin{array}{c}\text { Intermediate } 1 \\
\mathrm{~N}=64\end{array}$}} & \multirow{2}{*}{\multicolumn{2}{|c|}{$\begin{array}{c}\text { Intermediate } 2 \\
\mathrm{~N}=62\end{array}$}} \\
\hline & & & & & \\
\hline & & 67 & range: $40-80$ & 69 & range: $39-83$ \\
\hline & & \multicolumn{2}{|l|}{$\begin{array}{l}\text { Number of } \\
\text { patients }\end{array}$} & \multicolumn{2}{|l|}{$\begin{array}{l}\text { Number of } \\
\text { patients }\end{array}$} \\
\hline \multirow[t]{2}{*}{ Sex } & Male & 53 & & 46 & \\
\hline & Female & 11 & & 16 & \\
\hline \multirow[t]{2}{*}{ Number of metastatic organs } & Single & 39 & & 36 & \\
\hline & Multiple & 25 & & 26 & \\
\hline \multirow[t]{6}{*}{ Sites of metastasis } & Lung & 46 & & 45 & \\
\hline & Lymph node & 12 & & 16 & \\
\hline & Bone & 18 & & 15 & \\
\hline & Pancreas & 4 & & 2 & \\
\hline & Liver & 3 & & 4 & \\
\hline & Brain & 2 & & 2 & \\
\hline \multirow{5}{*}{$\begin{array}{l}\text { Positive factors in the } \\
\text { Memorial Sloan Kettering } \\
\text { Cancer Center criteria }\end{array}$} & Performance status & 8 & & 35 & \\
\hline & Serum hemoglobin level & 16 & & 36 & \\
\hline & $\begin{array}{l}\text { Time from diagnosis to } \\
\text { treatment }\end{array}$ & 33 & & 40 & \\
\hline & Corrected calcium level & 4 & & 6 & \\
\hline & Lactate dehydrogenase level & 3 & & 7 & \\
\hline \multirow[t]{4}{*}{1 st-line treatment } & Sunitinib & 38 & & 39 & \\
\hline & Sorafenib & 23 & & 16 & \\
\hline & Pazopanib & 2 & & 3 & \\
\hline & Temsirolimus & 1 & & 4 & \\
\hline
\end{tabular}

it has not been decided whether it is appropriate to treat the intermediate-risk group as one group. In our analysis, the OS of the Int- 1 and Int-2 groups were 43.6 and 22.5 months, respectively, indicating that the prognosis of the latter group was significantly poorer (log-rank test, $\mathrm{p}=0.017$ ). The most common positive risk factor in both groups was PS, followed by anemia. This finding suggests that the aggravation of PS and anemia may possibly have an influence on prognosis in both groups. Sella et al. [9] reported that they found a difference in OS and PFS between the Int- 1 and Int-2 groups and in PFS and the objective response rate among patients with Eastern Cooperative Oncology Group PS $\geq 1$. These analyses were compiled from the results of six clinical trials, and a conclusion was reached that segmenting the intermediaterisk group and stratification by PS are necessary. Our real- 


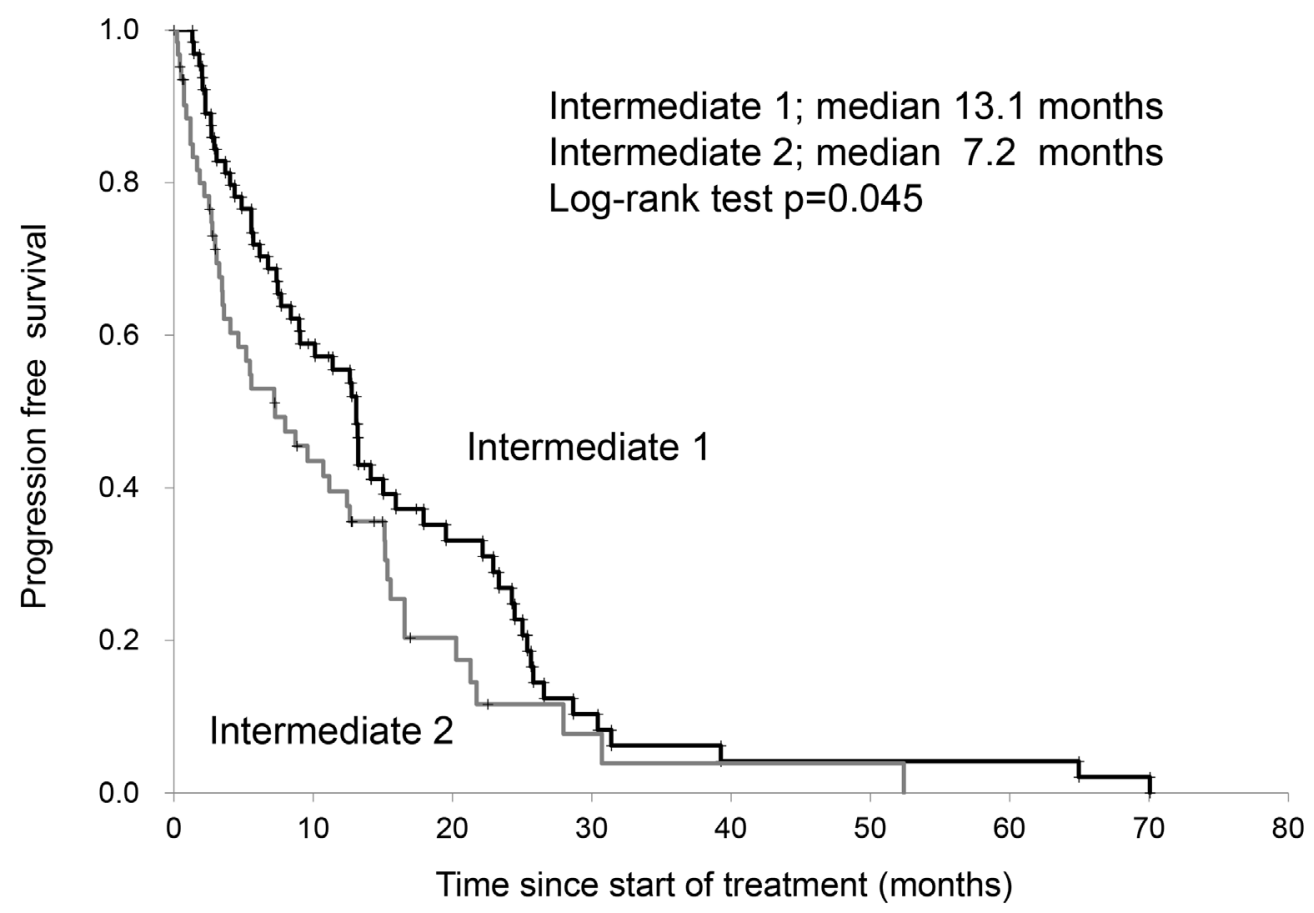

No. at risk

$\begin{array}{lllllllll}\text { Intermediate 1 } & 64 & 36 & 17 & 6 & 8 & 3 & 2 & 1 \\ \text { Intermediate 2 } & 62 & 23 & 8 & 3 & 2 & 2 & 0 & \end{array}$

Figure 1: Progression-free survival of patients with 1 versus those with 2 risk factors in the Memorial Sloan Kettering Cancer Center risk classification.

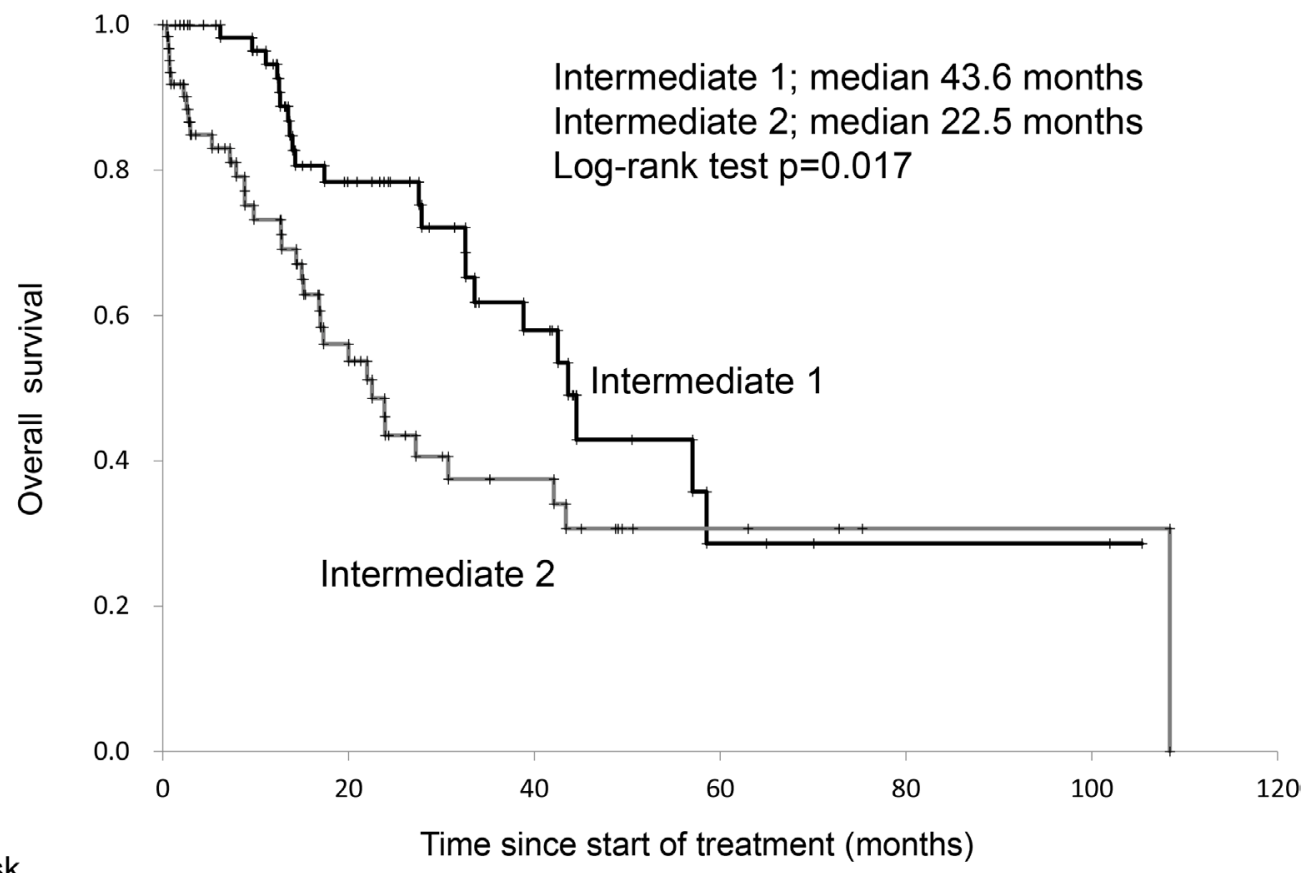

No. at risk

Intermediate $1 \quad 64$

34

16

Intermediate $2 \quad 62$

24

12

$\begin{array}{lll}5 & 3 & 2 \\ 5 & 2 & 1\end{array}$

Figure 2: Overall survival of patients with 1 versus those with 2 risk factors in the Memorial Sloan Kettering Cancer Center risk classification. 
Table 3: Results of the Cox proportional stepwise multivariate analysis for the association between the variables and overall survival

\begin{tabular}{|c|c|c|c|c|c|c|c|c|c|}
\hline \multirow{2}{*}{\multicolumn{3}{|c|}{ Comparison }} & \multirow{2}{*}{\multicolumn{3}{|c|}{$\begin{array}{l}\text { Overall survival } \\
\text { (months), median }\end{array}$}} & \multicolumn{2}{|c|}{ Unadjusted } & \multicolumn{2}{|c|}{ Adjusted } \\
\hline & & & & & & \multirow{2}{*}{$\begin{array}{c}\text { HR }(\mathbf{9 5 \%} \mathbf{C I}) \\
1.27(0.74-2.18)\end{array}$} & \multirow{2}{*}{$\frac{\text { p value }}{0.381}$} & \multirow{2}{*}{$\begin{array}{c}\text { HR }(\mathbf{9 5 \%} \text { CI) } \\
1.38(0.80-2.38)\end{array}$} & \multirow{2}{*}{$\begin{array}{c}\text { p value } \\
0.239\end{array}$} \\
\hline $\begin{array}{l}\text { Metastasis in } \\
\text { a single organ }\end{array}$ & vs & $\begin{array}{l}\text { Metastasis in } \\
\text { multiple organs }\end{array}$ & 38.8 & vs & 30.7 & & & & \\
\hline Int-1 & vs & Int-2 & 43.6 & vs & 22.5 & $1.93(1.12-3.33)$ & 0.017 & $1.91(1.11-3.30)$ & 0.019 \\
\hline $\begin{array}{l}\text { Presence of } \\
\text { pancreatic } \\
\text { metastasis }\end{array}$ & vs & $\begin{array}{l}\text { Absence of } \\
\text { pancreatic } \\
\text { metastasis }\end{array}$ & 32.6 & vs & $\begin{array}{l}\text { not } \\
\text { reached }\end{array}$ & $0.19(0.02-1.40)$ & 0.103 & $0.18(0.02-1.38)$ & 0.100 \\
\hline
\end{tabular}

Abbreviations: HR, hazard ratio; CI, confidence interval.

world data supports this conclusion. In addition, the mean survivals in the favorable- and poor-risk groups in the MSKCC study were 91.0 and 15.2 months, respectively. Since the difference in these groups was greater than that in the Int-1 group, prognosis prediction and treatment approach should be treated in a separate study group.

We showed in our previous study that the presence or absence of pancreatic metastasis and the number of metastatic organs, as well as the MSKCC classification, had an influence on prognosis [10]. However, Shinohara et al. [8] advocated a risk classification designed for Japanese patients. They defined the following four items as the stratification factors: hemoglobin; less than 1 year from diagnosis to treatment; $\mathrm{LDH}$; and liver, bone, or multiple organs metastases. Consequently, they classified the favorable-risk group as 0-1 factor positive; the intermediate-risk group as 2 factors positive; and the poor-risk group as $\geq 3$ factors positive. Compared to the MSKCC risk classification, this classification additionally incorporated the metastatic organs or the number of metastatic organs as stratification factors, but it was reported that its correlation with life prognosis was as favorable as that of the MSKCC risk classification. In a multivariate analysis to assess the number of metastatic organs, however, it was revealed that the number of metastatic organs was not an independent factor that could affect the survival period of patients in the Int-1 and Int-2 groups. This finding suggests that the number of positive risk factors is more important than the number of metastatic organs in the intermediate-risk group.

In the present study, OS was 41.2 months, which is longer than that in large-scale clinical trials $[14,15]$. This may be influenced by the longer life expectancy of Japanese compared to other races. Furthermore, this may be due to the fact that Japanese have good treatment outcomes including other carcinomas [16]. However, Motzer et al. [17] reported that there were no differences in PFS or OS in Caucasian vs Asian patients. Conversely, there were significant differences in PFS and OS in Caucasians vs non-Caucasians, non-Asian patients.
Several investigators also showed that the survival period after the introduction of molecular targeted drugs seemed prolonged compared to that before their introduction [1, $3,4]$. Of the first-line treatment drugs, the survival period of the patients who used sunitinib was the longest. The survival period of patients who used temsirolimus was remarkably short, probably due to its use in the poor-risk group.

There were some limitations to this study; we conducted a retrospective study and the treatment drugs were not unified. Most of the patients in this study were enrolled at a time before the introduction of immunooncology drugs in the clinical management of $\mathrm{mRCC}$ patients; thus, the survival period may prolong if immunooncology drugs become more widely used in the future $[13,18,19]$. In particular, treatment results of immunooncology drugs among patients in the poor-risk group are much awaited. Another limitation is that we reported here the necessity of stratifying patients in the intermediaterisk group using the MSKCC criteria. The IMDC criteria, which is another risk classification, is now often adapted to mRCC patients. However, some of our study participants had no available data regarding neutrophil counts, especially those who were diagnosed before 2013; hence, we did not investigate the IMDC risk. Although the MSKCC criteria was established in the cytokine therapy era, we have in addition to other authors, showed that it can be applied efficiently to Japanese patients, even in the era of molecular targeted drugs $[8,10]$.

In conclusion, we found that patients in the intermediate-risk group based on the MSKCC risk classification had different prognoses, depending on the number of positive risk factors. Our finding will be helpful in the selection of a future treatment approach.

\section{MATERIALS AND METHODS}

We retrospectively analyzed 234 consecutively treated patients who had received molecular targeted drugs for mRCC. According to the therapeutic strategy in 
our institute, sorafenib was used as the first-line therapy and sunitinib or everolimus as the second-line therapy. However, since 2010, sunitinib has become the first-line therapy, and since 2012, axitinib has become the secondline therapy. We calculated OS and OS classified according to the MSKCC criteria. The OS period commenced from the time of treatment with the initial targeted therapy.

Next, we examined the difference between PFS and OS among patients in the intermediate-risk group of the MSKCC criteria. We divided the intermediate group into two subgroups as follows: patients who were positive for only one risk factor (Int-1) and those who were positive for two risk factors (Int-2) including performance status (PS), serum hemoglobin level, time from diagnosis to treatment, and corrected calcium and lactate dehydrogenase (LDH) levels. Subsequently, we investigated which factors had an influence on OS between the Int-1 and Int-2 groups.

OS was estimated using the Kaplan-Meier method and the differences were determined using the log-rank test. Cox proportional stepwise multivariate analysis was used to evaluate the association between the number of metastatic organs, Int- 1 or 2 grouping, presence or absence of pancreatic metastasis, and OS. A p-value $<0.05$ was considered statistically significant. All statistical analyses were performed using Microsoft Excel $^{\circledR}$ (Microsoft, Redmond, Washington, USA). Permission to access the database for a review of the medical records of these patients was obtained from the local research ethics committee at Osaka City University (approval number 3441).

\section{Abbreviations}

mRCC: metastatic renal cell carcinoma; MSKCC: Memorial Sloan Kettering Cancer Center; IMDC: International Metastatic Renal Cell Carcinoma Database Consortium; OS: overall survival; PFS: progressionfree survival; PS: performance status; LDH: lactate dehydrogenase; HR: hazard ratio; $\mathrm{CI}$ : confidence interval; ULN: upper limit of normal.

\section{Author contributions}

Conception and design, drafting of the manuscript: Satoshi Tamada.

Acquisition of data: Taro Iguchi, Minoru Kao, Takeshi Yamasaki.

Analysis and interpretation of data: Satoshi Tamada, Sayaka Yasuda.

Final approval of the manuscript: Tatsuya Nakatani.

\section{ACKNOWLEDGMENTS}

We would like to thank Ms. Ayako Akagi for data collection, Mr. Maehira (https://www.igaku-honyaku. $\mathrm{jp} /$ ) and Editage (www.editage.jp) for English language editing.

\section{CONFLICTS OF INTEREST}

S. Tamada received remuneration for a lecture from Pfizer Japan (Tokyo, Japan), Bayer Japan (Tokyo, Japan) and Novartis Pharma Japan (Tokyo, Japan). The other authors have declared no conflicts of interest.

\section{FUNDING}

None.

\section{REFERENCES}

1. Motzer RJ, Escudier B, Gannon A, Figlin RA. Sunitinib: Ten Years of Successful Clinical Use and Study in Advanced Renal Cell Carcinoma. Oncologist. 2017; 22:41-52.

2. Ninomiya N, Tamada S, Kato M, Yamasaki T, Iguchi T, Nakatani T. Prolonging survival in metastatic renal cell carcinoma patients treated with targeted anticancer agents: a single-center experience of treatment strategy modifications. Can J Urol. 2015; 22:7798-804.

3. Wahlgren T, Harmenberg U, Sandström P, Lundstam S, Kowalski J, Jakobsson M, Sandin R, Ljungberg B. Treatment and overall survival in renal cell carcinoma: a Swedish population-based study (2000-2008). Br J Cancer. 2013; 108:1541-49.

4. Lindskog $M$, Wahlgren $T$, Sandin R, Kowalski J, Jakobsson M, Lundstam S, Ljungberg B, Harmenberg U. Overall survival in Swedish patients with renal cell carcinoma treated in the period 2002 to 2012: update of the RENCOMP study with subgroup analysis of the synchronous metastatic and elderly populations. Urol Oncol. 2017; 35:541.e15-22.

5. Motzer RJ, Bacik J, Murphy BA, Russo P, Mazumdar M. Interferon-alfa as a comparative treatment for clinical trials of new therapies against advanced renal cell carcinoma. J Clin Oncol. 2002; 20:289-96.

6. Motzer RJ, Hutson TE, Tomczak P, Michaelson MD, Bukowski RM, Oudard S, Negrier S, Szczylik C, Pili R, Bjarnason GA, Garcia-del-Muro X, Sosman JA, Solska E, et al. Overall survival and updated results for sunitinib compared with interferon alfa in patients with metastatic renal cell carcinoma. J Clin Oncol. 2009; 27:3584-90.

7. Heng DY, Xie W, Regan MM, Harshman LC, Bjarnason GA, Vaishampayan UN, Mackenzie M, Wood L, Donskov F, Tan MH, Rha SY, Agarwal N, Kollmannsberger C, et al. External validation and comparison with other models of the International Metastatic Renal-Cell Carcinoma Database Consortium prognostic model: a population-based study. Lancet Oncol. 2013; 14:141-48. 
8. Shinohara N, Obara W, Tatsugami K, Naito S, Kamba T, Takahashi M, Murai S, Abe T, Oba K, Naito S. Prognosis of Japanese patients with previously untreated metastatic renal cell carcinoma in the era of molecular-targeted therapy. Cancer Sci. 2015; 106:618-26.

9. Sella A, Michaelson MD, Matczak E, Simantov R, Lin X, Figlin RA. Heterogeneity of Patients With IntermediatePrognosis Metastatic Renal Cell Carcinoma Treated With Sunitinib. Clin Genitourin Cancer. 2017; 15:291-299. e1.

10. Shimizu Y, Iguchi T, Tamada S, Yasuda S, Kato M, Ninomiya N, Yamasaki T, Nakatani T. Oncological outcomes classified according to metastatic lesions in the era of molecular targeted drugs for metastatic renal cancer. Mol Clin Oncol. 2018; 8:791-96.

11. Miyake H, Miyazaki A, Harada K, Fujisawa M. Assessment of efficacy, safety and quality of life of 110 patients treated with sunitinib as first-line therapy for metastatic renal cell carcinoma: experience in real-world clinical practice in Japan. Med Oncol. 2014; 31:978.

12. Choueiri TK, Halabi S, Sanford BL, Hahn O, Michaelson MD, Walsh MK, Feldman DR, Olencki T, Picus J, Small EJ, Dakhil S, George DJ, Morris MJ. Cabozantinib Versus Sunitinib As Initial Targeted Therapy for Patients With Metastatic Renal Cell Carcinoma of Poor or Intermediate Risk: The Alliance A031203 CABOSUN Trial. J Clin Oncol. 2017; 35:591-97.

13. Motzer RJ, Tannir NM, McDermott DF, Arén Frontera O, Melichar B, Choueiri TK, Plimack ER, Barthélémy P, Porta C, George S, Powles T, Donskov F, Neiman V, et al, and CheckMate 214 Investigators. Nivolumab plus Ipilimumab versus Sunitinib in Advanced Renal-Cell Carcinoma. N Engl J Med. 2018; 378:1277-90.

14. Motzer RJ, Hutson TE, Tomczak P, Michaelson MD, Bukowski RM, Rixe O, Oudard S, Negrier S, Szczylik
C, Kim ST, Chen I, Bycott PW, Baum CM, Figlin RA. Sunitinib versus interferon alfa in metastatic renal-cell carcinoma. N Engl J Med. 2007; 356:115-24.

15. Motzer RJ, Hutson TE, Cella D, Reeves J, Hawkins R, Guo J, Nathan P, Staehler M, de Souza P, Merchan JR, Boleti E, Fife K, Jin J, et al. Pazopanib versus sunitinib in metastatic renal-cell carcinoma. N Engl J Med. 2013; 369:722-31.

16. Allemani C, Matsuda T, Di Carlo V, Harewood R, Matz M, Nikšić M, Bonaventure A, Valkov M, Johnson CJ, Estève J, Ogunbiyi OJ, Azevedo E Silva G, Chen WQ, et al, and CONCORD Working Group. Global surveillance of trends in cancer survival 2000-14 (CONCORD-3): analysis of individual records for 37513025 patients diagnosed with one of 18 cancers from 322 population-based registries in 71 countries. Lancet. 2018; 391:1023-75.

17. Motzer RJ, Escudier B, Bukowski R, Rini BI, Hutson TE, Barrios CH, Lin X, Fly K, Matczak E, Gore ME. Prognostic factors for survival in 1059 patients treated with sunitinib for metastatic renal cell carcinoma. Br J Cancer. 2013; 108:2470-77.

18. Motzer RJ, Escudier B, McDermott DF, George S, Hammers HJ, Srinivas S, Tykodi SS, Sosman JA, Procopio G, Plimack ER, Castellano D, Choueiri TK, Gurney H, et al, and CheckMate 025 Investigators. Nivolumab versus Everolimus in Advanced Renal-Cell Carcinoma. N Engl J Med. 2015; 373:1803-13.

19. Atkins MB, Plimack ER, Puzanov I, Fishman MN, McDermott DF, Cho DC, Vaishampayan U, George S, Olencki TE, Tarazi JC, Rosbrook B, Fernandez KC, Lechuga M, Choueiri TK. Axitinib in combination with pembrolizumab in patients with advanced renal cell cancer: a non-randomised, open-label, dose-finding, and dose-expansion phase 1b trial. Lancet Oncol. 2018; 19:405-15. 